\title{
STRATIGRAPHIC ARCHITECTURE AND RESERVOIR CHARACTERIZATION OF THE SILURIAN RACINE FORMATION, FORSYTH FIELD, CENTRAL ILLINOIS
}

Yaghoob Lasemi

Illinois State Geological Survey, University of Illinois at Urbana-Champaign

Geological Society of America Annual Meeting, October 2017

4 illinois state 


\section{Acknowledgements}

This work is partially funded by the U.S. Department of Energy - National Energy Technology Laboratory through CarbonSAFE Illinois-Macon County Grant No. DEFE0029381 (Steven G. Whittaker PI). Original draft of contour maps and cross-sections were prepared using IHS PETRA through their University Grant Program. 


\section{Presentation Outline}

1. Geologic setting

2. Field discovery and development

3. Stratigraphy and reservoir characterization

4. Reservoir development and petroleum entrapment

5. Potential for future development 




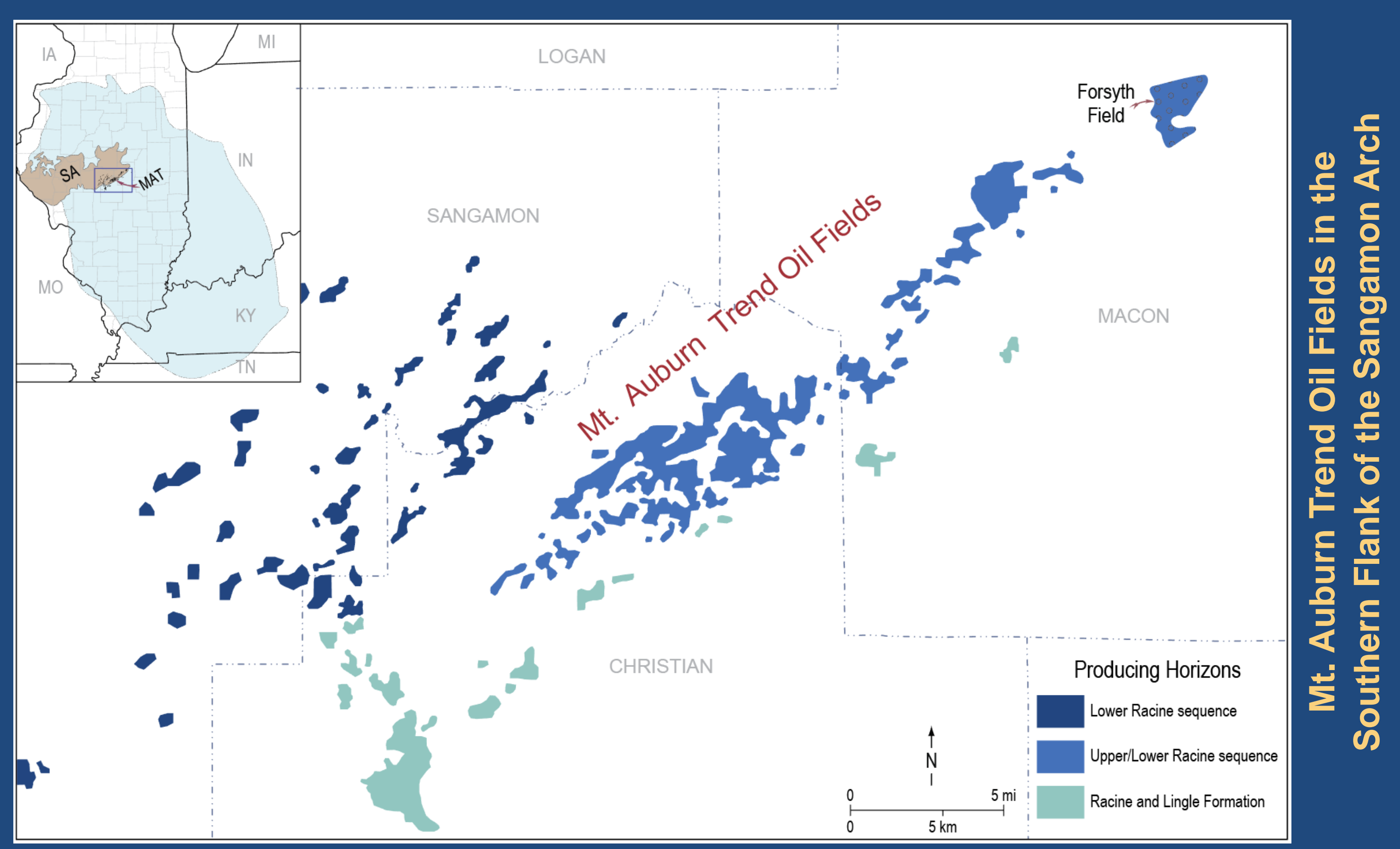


Stratigraphy and Correlation 




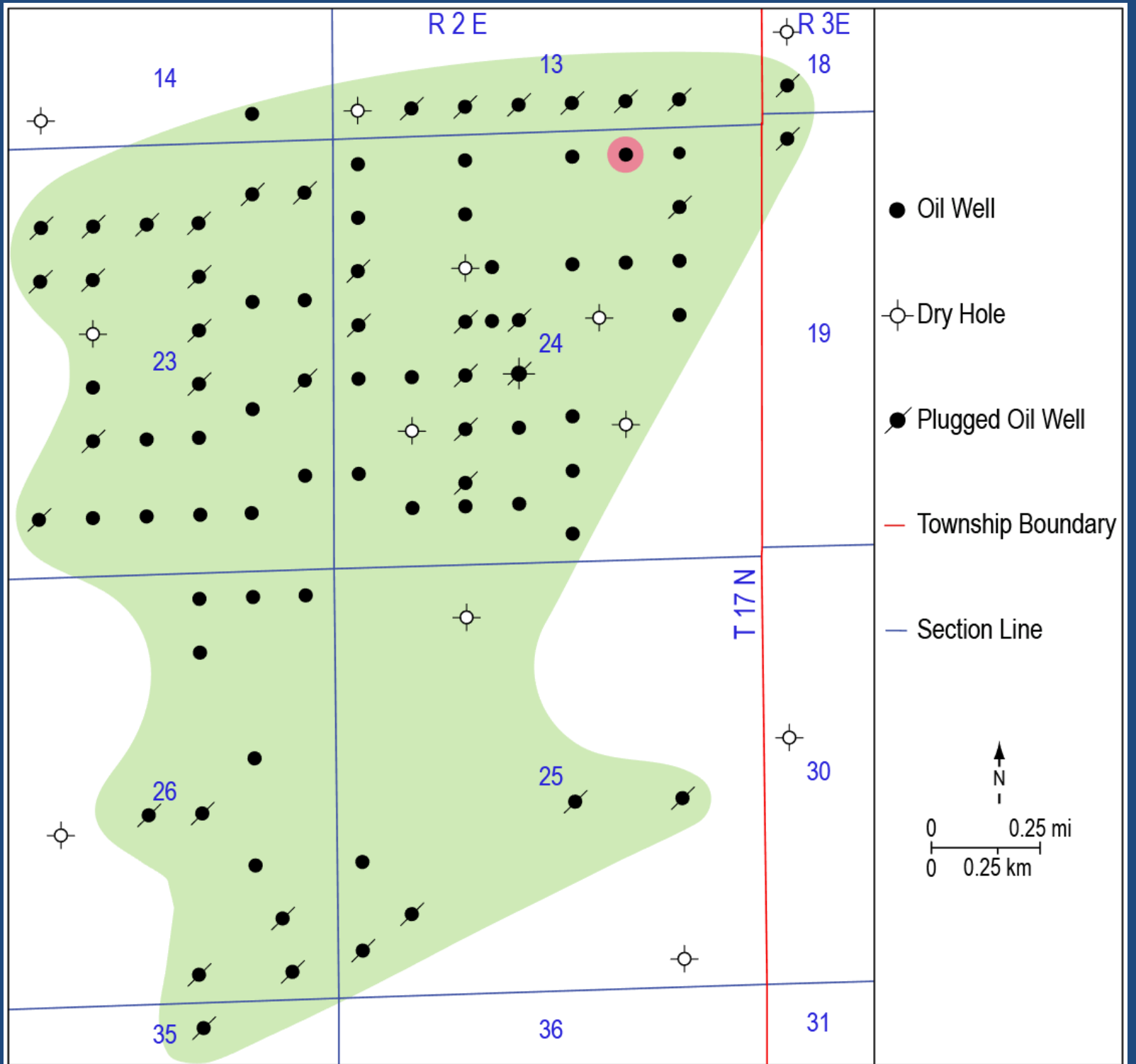

Stratigraphic Reference Section (SchwarzePense Com. No. 2, API \#121152144400)

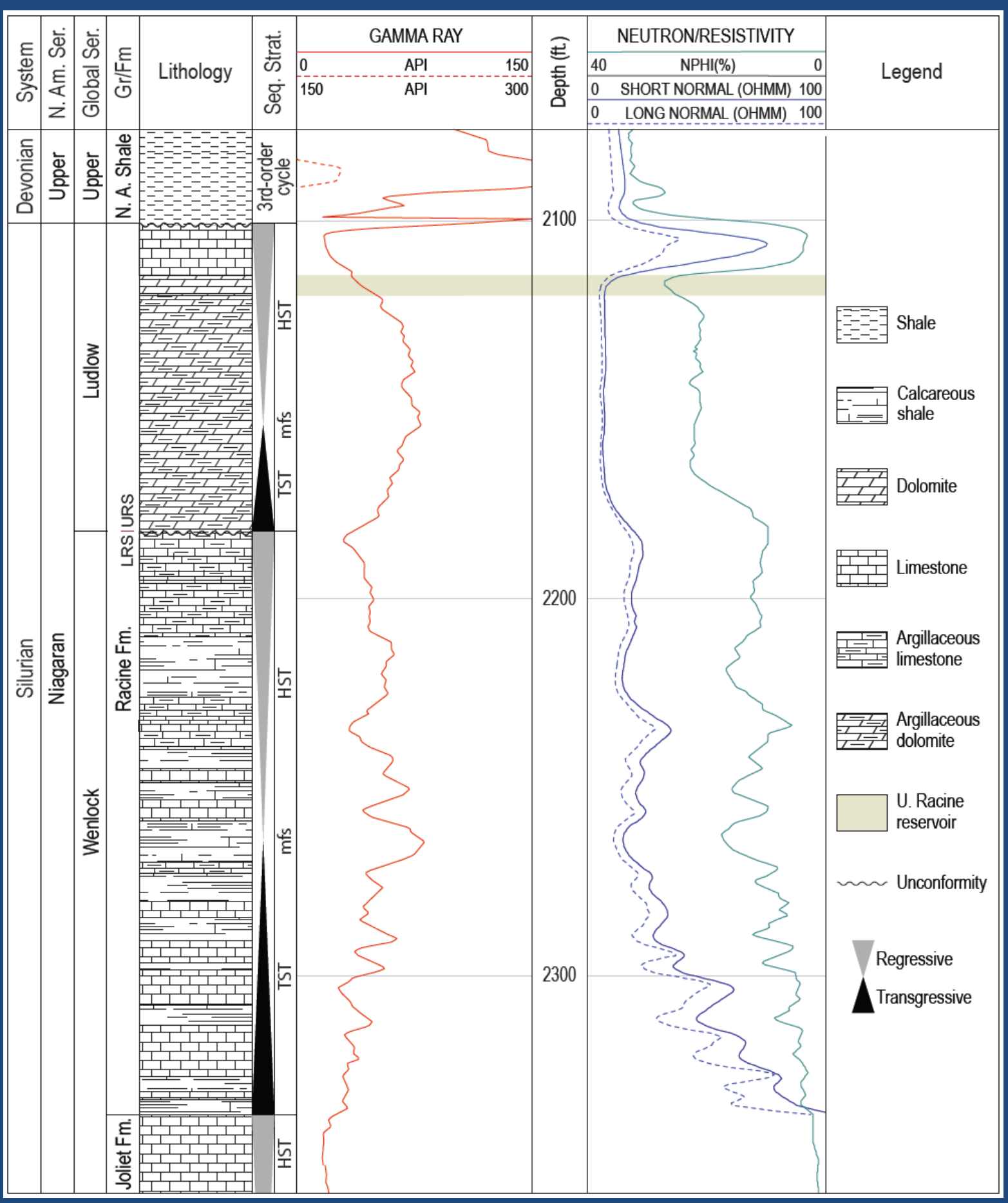


Reservoir Occurrence and Variability 





NW $\quad$ Hockaday No. 7 (API\#121152139600)

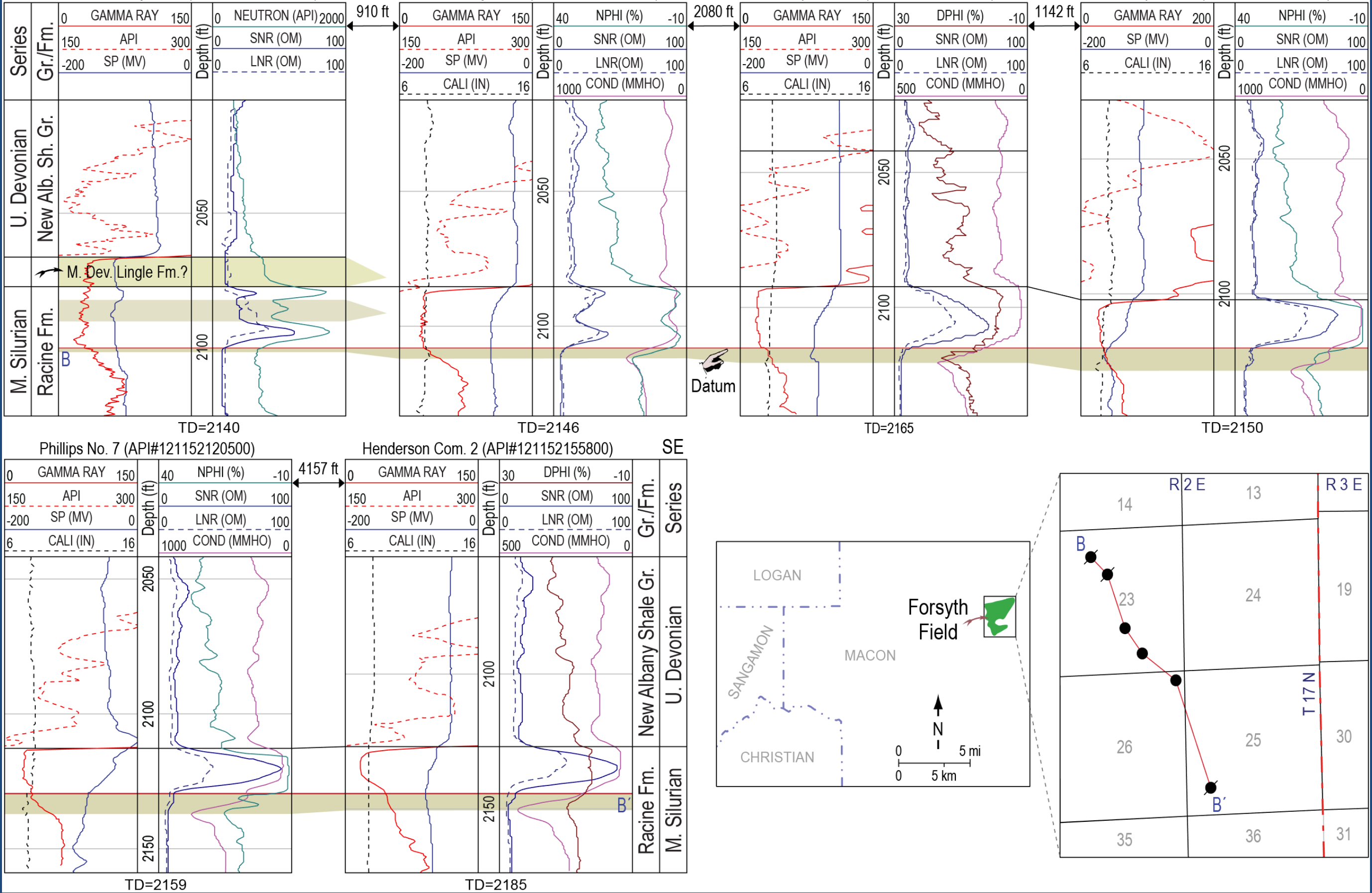




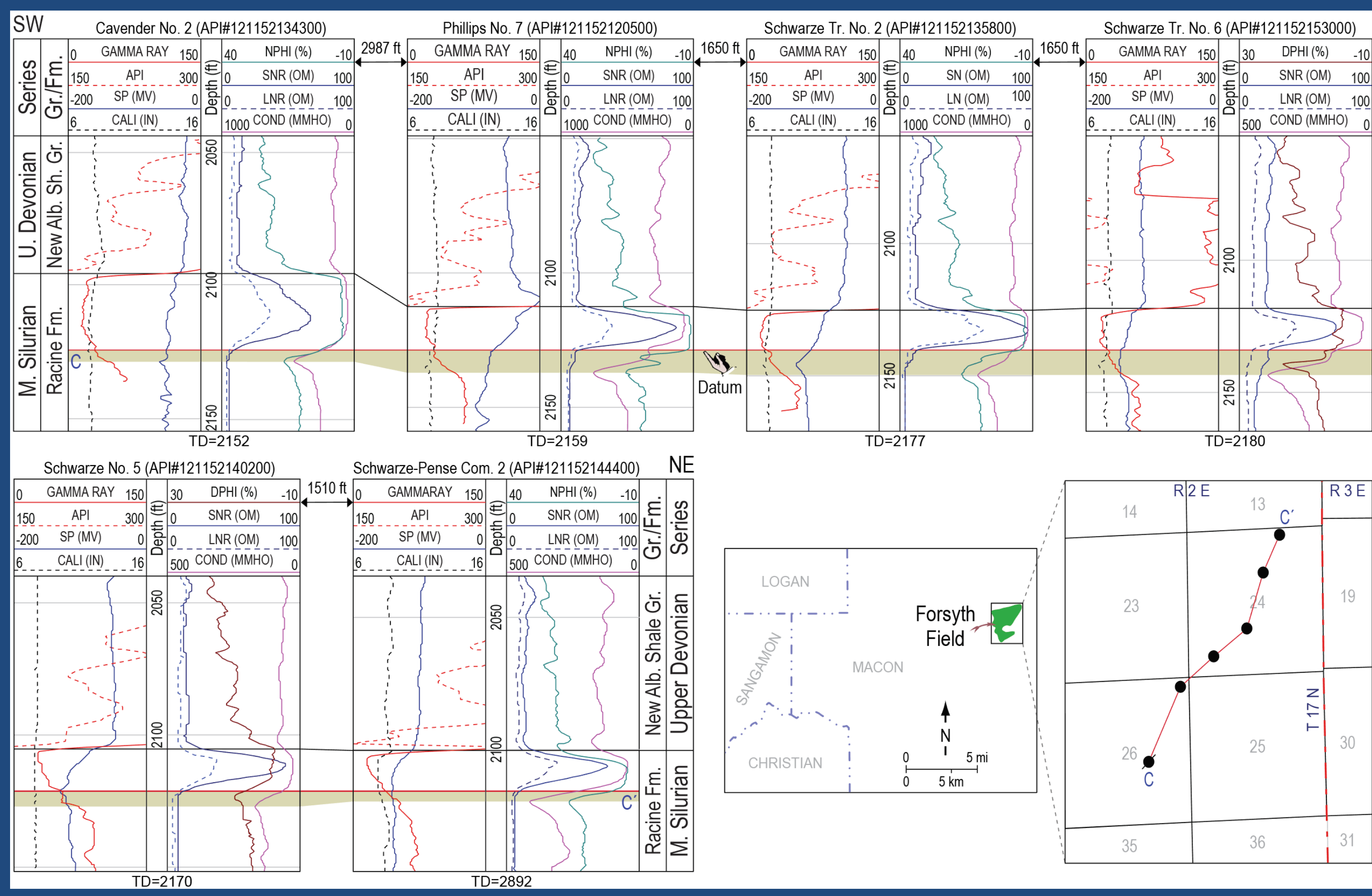




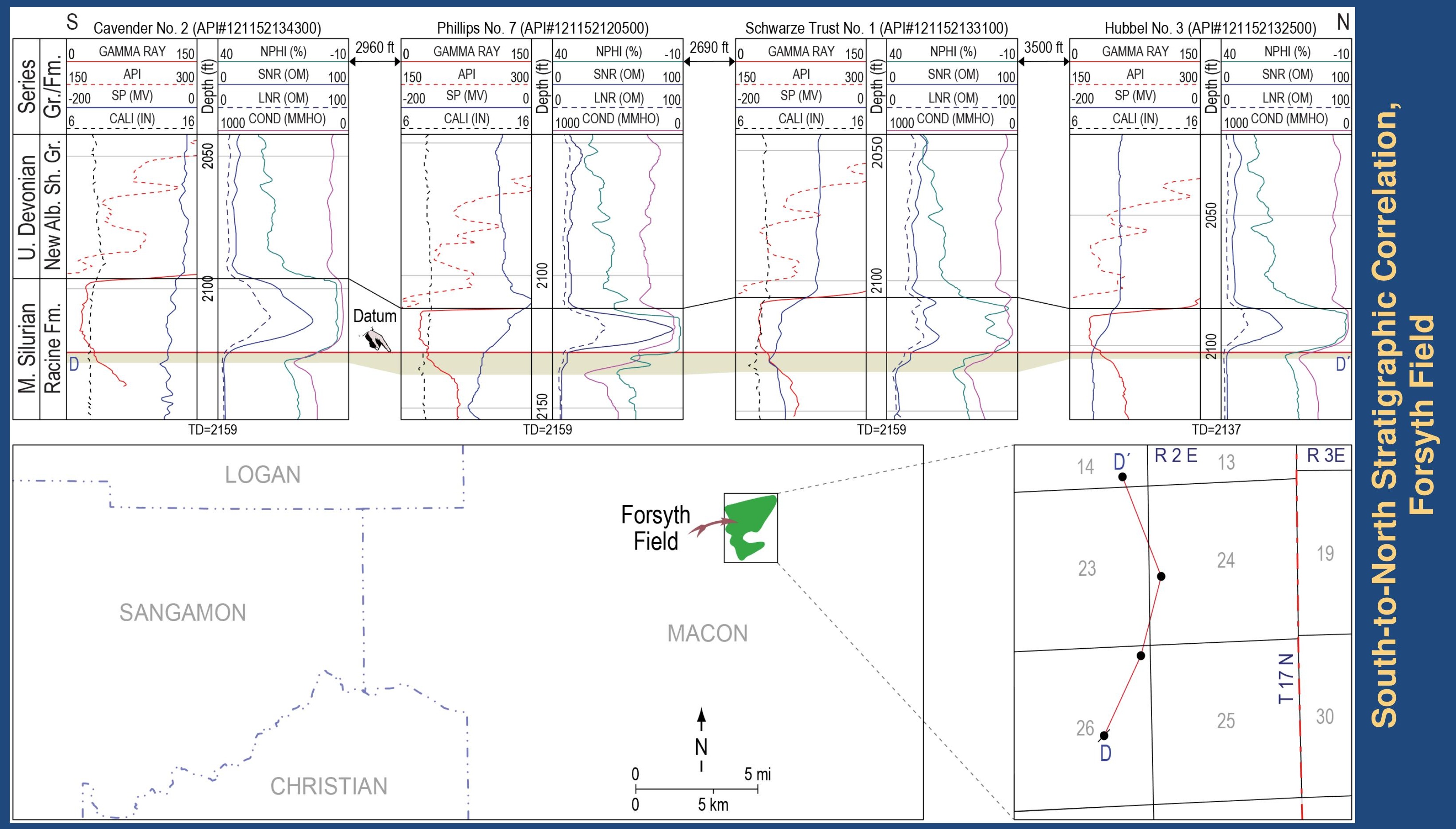




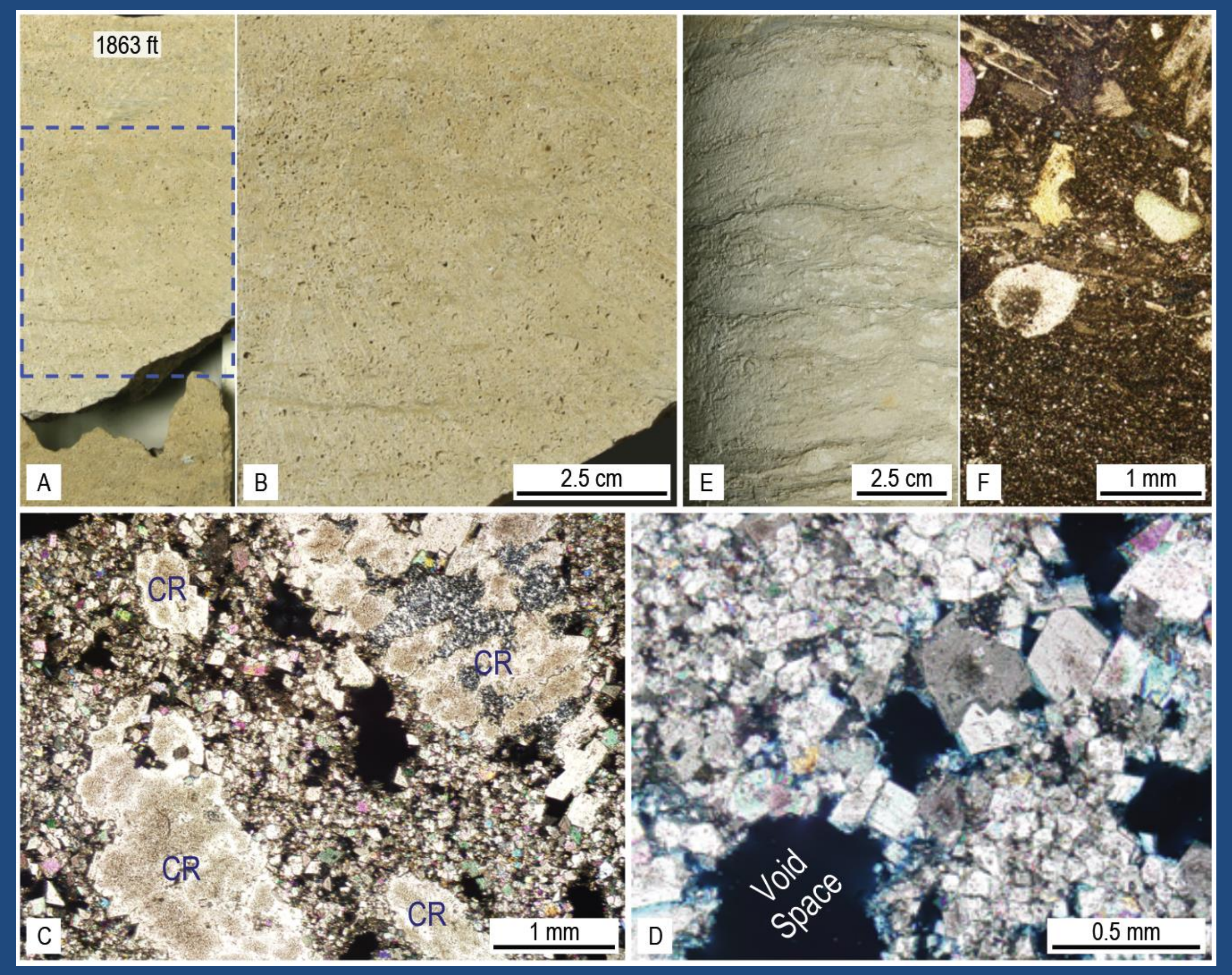

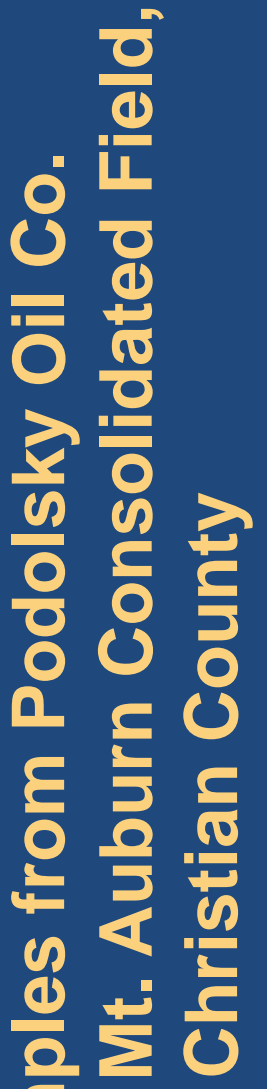

ह

क ต

ᄋ 을 


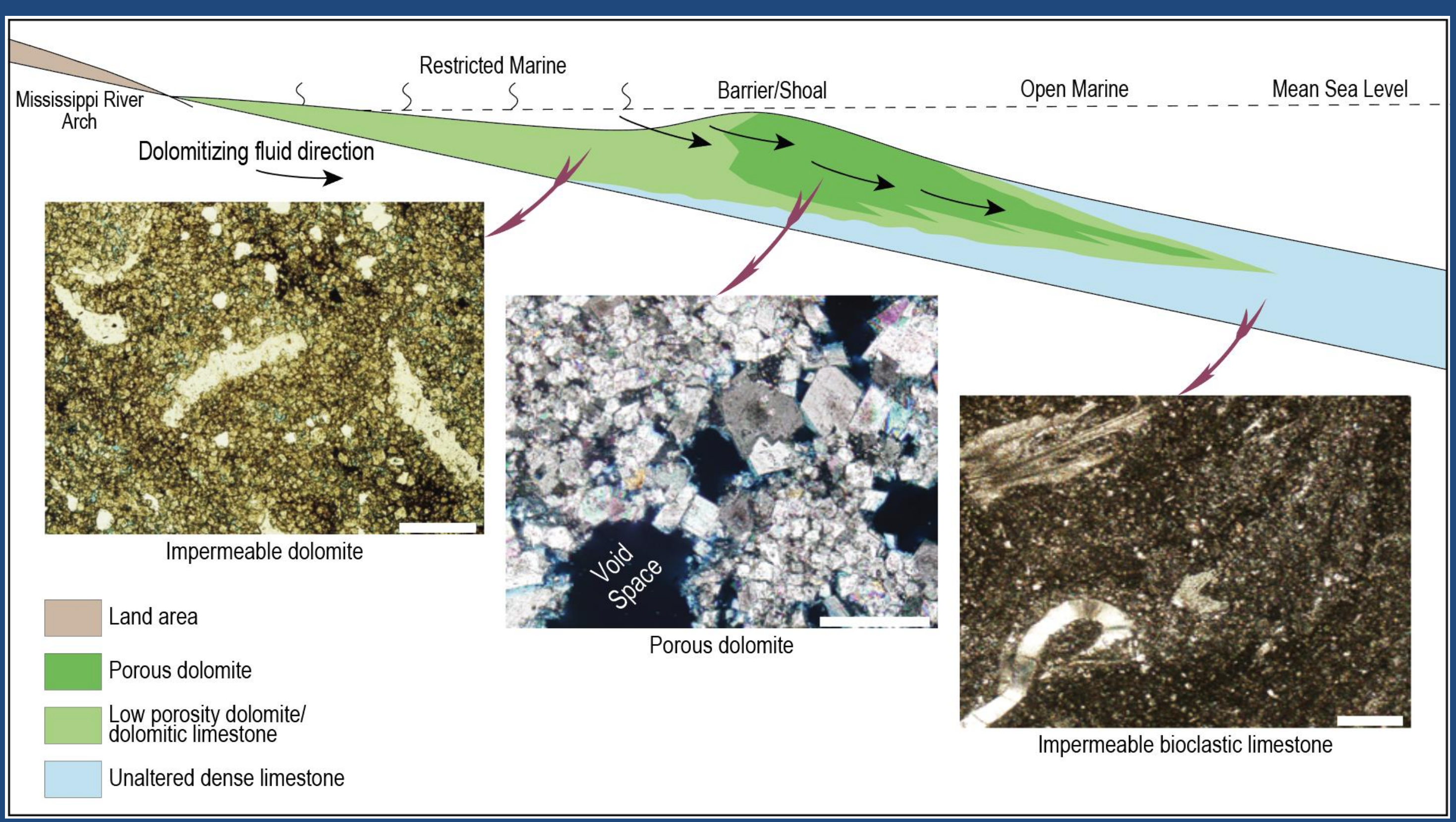

Depositional and Diagenetic Model for Reservoir Development in the Silurian Deposits of the Study Area (Photomicrograph Scale Bar: $0.5 \mathrm{~mm}$ ) 




Thickness Map of the Main Reservoir



Reservoir Top Structure Contour Map 


\section{Potential for Improving Recovery}


Poor Reservoir Performance

1. Calculated OOIP: Over $10,000,000$ barrels.

2. Production per well: Less than $10,000 \mathrm{bbl}$./solution gas and gravity drive.

3. DST: Low SIP and negligible fluid recovery.

4. Initial oil production: Nearly 40 bbl. Average.

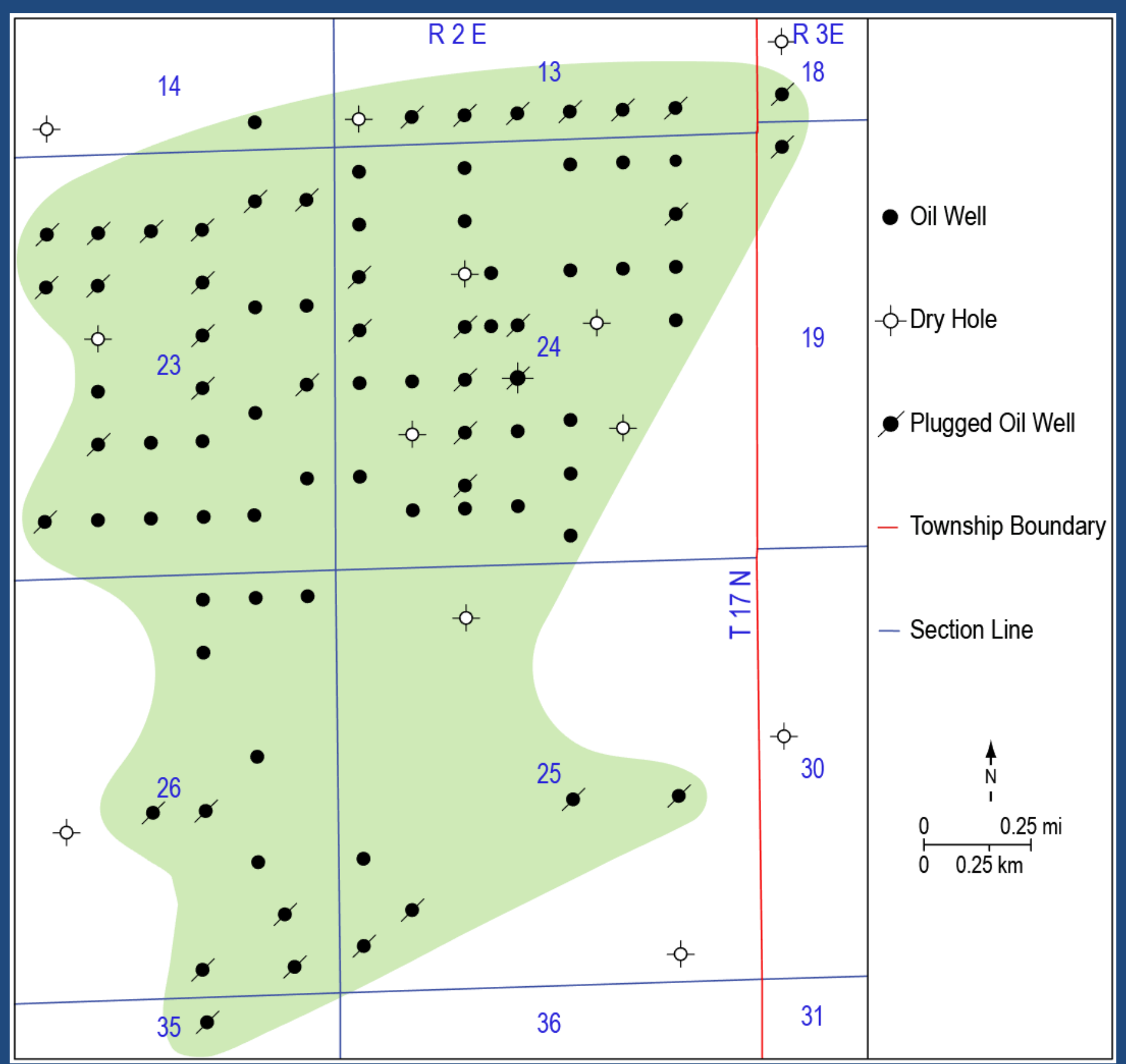




\section{Suggestions for Increased Production}

1. Infill drilling.

2. Development of undrilled areas.

3. Larger volume hydraulic fracturing.

4. Horizontal drilling.

5. Enhanced recovery through waterflooding or $\mathrm{CO}_{2} \mathrm{EOR}$.

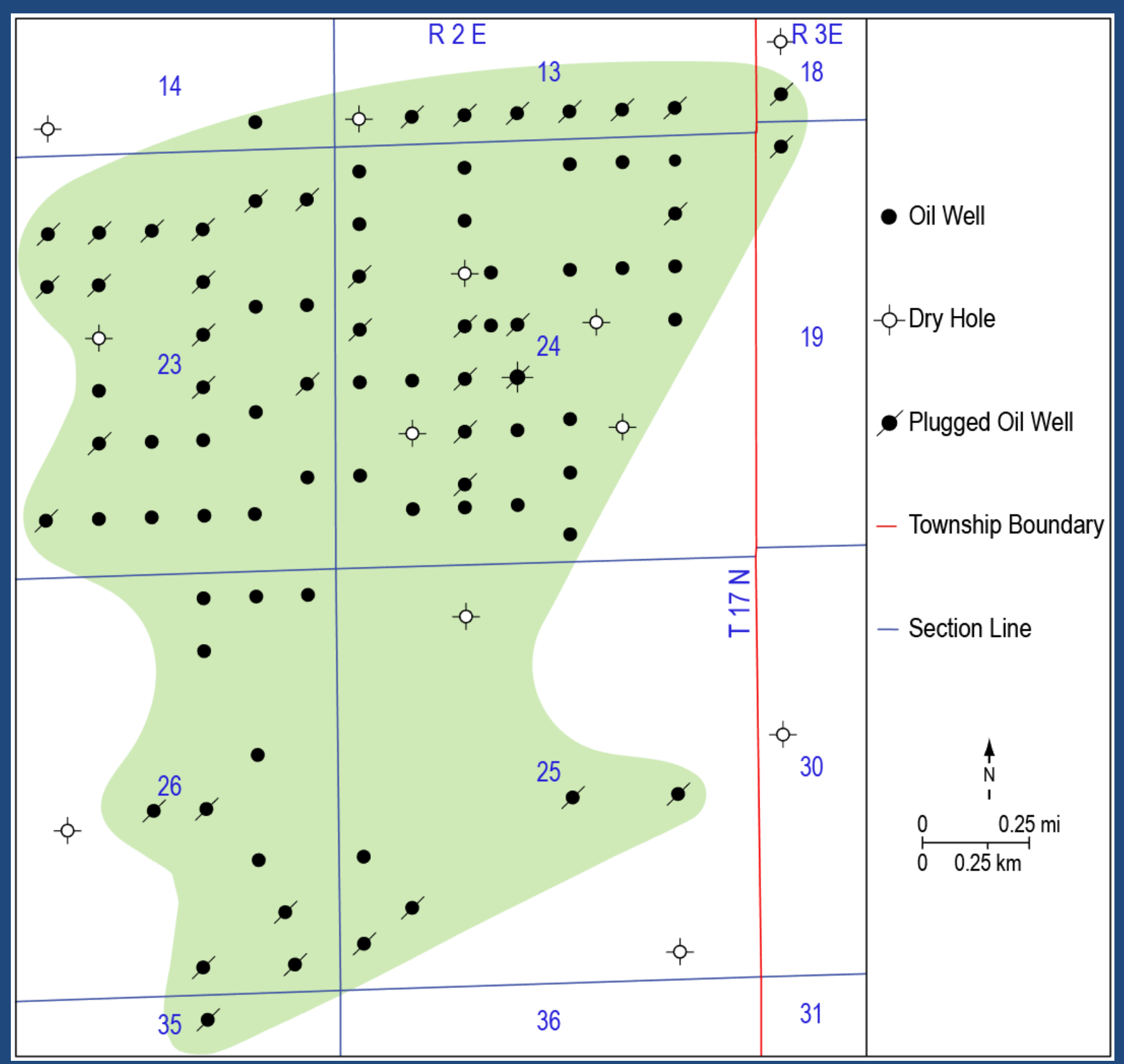




\section{Conclusions}

$\square$ The Silurian reservoir interval at Forsyth consists of dolomite bodies that occur in the upper part of small scale cycles, which suggest sea level fluctuation as the major control for their development.

$\square$ Low recorded shut-in pressure and negligible fluid recovery in DST, insignificant initial oil production, and below average cumulative primary production per well suggest poor permeability.

- Infill drilling and development of the undrilled areas, large volume hydraulic fracturing, and horizontal drilling could lead to significant increased production from the field.

$\square$ The field has produced less than $10 \%$ of its OOIP and has never been flooded. It has a great potential for significant increased recovery through waterflooding and CO2-EOR. 
Thank You 